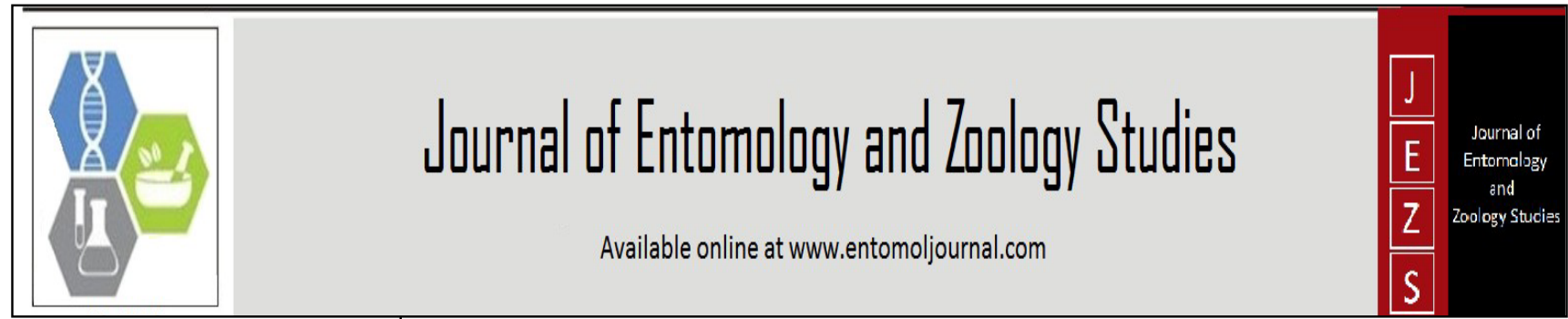

E-ISSN: 2320-7078 P-ISSN: 2349-6800 JEZS 2016; 4(2): 509-510

(C) 2016 JEZS

Received: 02-02-2016

Accepted: 05-03-2016

Mark Ian Cooper

Department of Biological Sciences, Private Bag X3, University of Cape Town, Rondebosch 7701, South Africa.
Correspondence

Mark Ian Cooper

Department of Biological

Sciences, Private Bag X3,

University of Cape Town,

Rondebosch 7701, South Africa.

\section{Heavier-shorter-wider females in the millipede Centrobolus inscriptus Attems (Spirobolida: Trigoniulidae)}

\section{Mark Ian Cooper}

\section{Abstract}

Millipedes have asymptotic or determinate growth and adult body sizes are fixed and can be measured with minimum error. Intraspecific variance in sexual size dimorphism (mass, length, width) was studied in Centrobolus inscriptus. There was continuous dimorphism in mass with males normally distributed and females were skewed towards having a larger mass. Length was continuous but the female distribution was skewed towards shorter individuals. Width shows nearly total discontinuity and was strongly skewed towards wider females and intermediate males.

Keywords: arthropod, Centrobolus, dimorphism, diplopod, millipede, size

\section{Introduction}

Millipedes have asymptotic or determinate growth which means that adult body sizes are fixed and can be measured with minimum error ${ }^{[1]}$. Centrobolus millipedes obey Rensch's Rule as females are larger and there is a steady rise in sexual size dimorphism with overall body size with the allometric coefficient of $0.85^{[2]}$. This allometric finding was also made by earlier myriapodologists ${ }^{[3]}$. The size of a millipede is not completely understood, especially intraspecific variance. The distributions of three factors which contribute towards intraspecific sexual size dimorphism in $C$. inscriptus: mass, length and horizontal width, were examined. The null hypothesis was that there was no directional distribution in any of these factors. The alternative hypotheses was that there was directional distribution towards heavier-shorterwider females and lighter-longer-thinner males.

\section{Materials and Methods}

C. inscriptus were collected during the rainy season (February 1996) at Twin Streams Farm ( $\left.28^{\circ} 55^{\prime} \mathrm{S}, 31^{\circ} 45^{\prime} \mathrm{E}\right)$. Males and females were measured in the same manner using the same scale so that both measurement and intrinsic errors were alike for both sexes. Body length $(\mathrm{mm})$ was measured by placing individuals alongside a plastic rule, horizontal width (mm) was measured with vernier scale calipers, mass (accurate to $0.01 \mathrm{~g}$ ) taken by placing animals directly on a Mettler balance, for all the collected males and females of $C$. inscriptus.

\section{Results}

Although there was continuous dimorphism in mass, males are normally distributed and females are skewed towards having a larger mass (Figure 1a). The double peak represents a possible population disruption and directional selection for heavier females. Length was also continuous however the female distribution was skewed towards shorter individuals (Figure 1b). Horizontal width shows nearly total discontinuity and was strongly skewed towards wider females and intermediate males (Figure 1c). The arcsine of length: width ratios places the sexes as equally apart as was the distribution for width (Figure 1d). The combination of these two parameters may be perceived as sexual size dimorphism as represented by the distribution of body volumes (Cooper, In Press) ${ }^{[2]}$. 
(a)

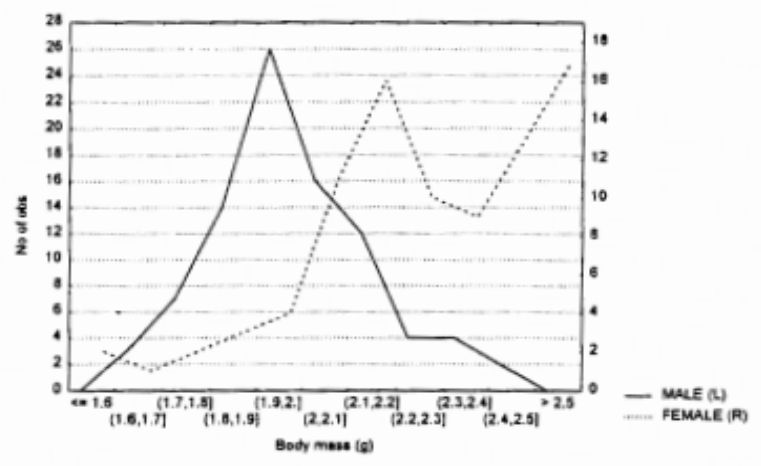

(b)

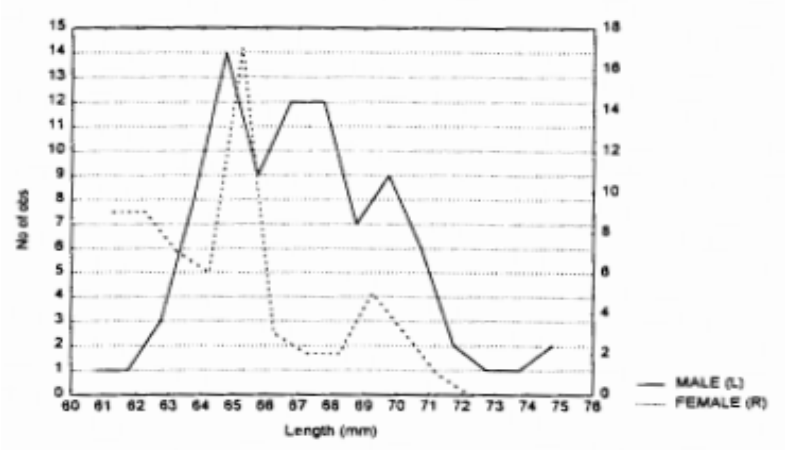

(c)

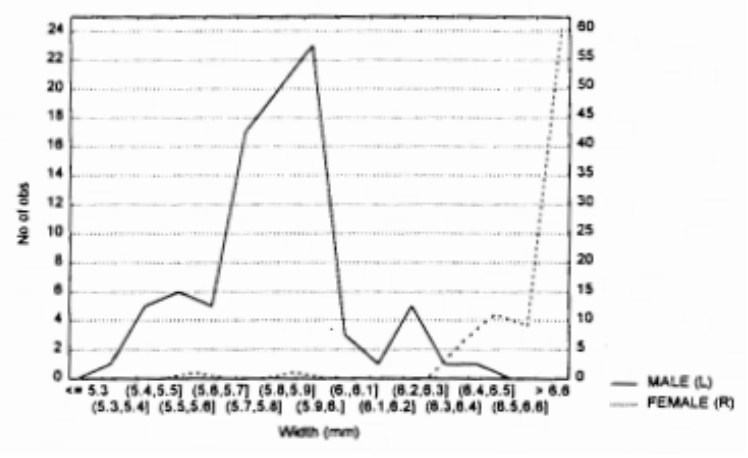

(d)

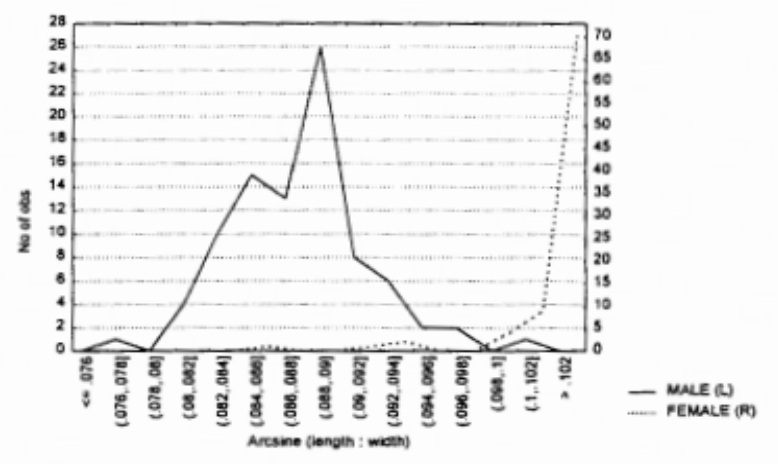

Fig 1: The sexual differences in the distribution of mass, length and horizontal width (a-c), and the ratio calculated between the latter two (d), for the trigoniulus millipede Centrobolus inscriptus from a population sampled during the mating season.
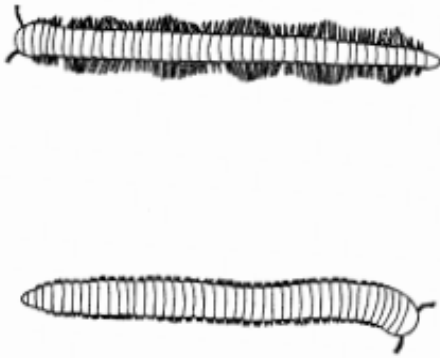

Fig 2: Outlined dorsal views of a male (above) and a female (below) trigoniulus millipede Centrobolus inscriptus, a species showing continuous dimorphism in mass and length but discontinuous dimorphism in horizontal width (mean sexual size dimorphism is 1.3 female body volume / male body volume).

\section{Discussion}

In 14 of 16 previous measures females were more variable than males in mass, length, horizontal width and volume ${ }^{[2]}$. In one exception, where the null hypotheses that the variances of the two sexes were equal, was submitted to a variance ratio test for which $\mathrm{F}$ was calculated as $\left(\mathrm{SD}_{\text {male }}\right)^{2} /$ $\left(\mathrm{SD}_{\text {female }}\right)^{2[4]}$. One exception was $C$. inscriptus where the null hypothesis was rejected and is perhaps a type I error as it should have been accepted because there appears to be genuinely higher variance in female body mass in $C$. inscriptus as indicated by the earlier finding of female mass being nearly twice as variable as male mass ${ }^{[2]}$. The sexual difference in horizontal body width agrees with the finding that width (and number of diplo-segments) are determinants of millipede size [5]. It has also been suggested that slenderness in males is important in sexual size dimorphism and is here illustrated by longer males and shorter females ${ }^{[5]}$. Sexual dimorphism in the millipede Cladethosoma clarum was attributed to females exhibiting greater body width and body mass compared with males ${ }^{[6]}$.

\section{Conclusion}

The sexual differences between male and female body plans that is observable in millipedes may be biologically significant. The variance in the female form, together with the distributions of the measurements taken for $C$. inscriptus, illustrate that although most dimorphism is continuous, there is directional selection for heavier-shorter-wider females.

\section{References}

1. Hopkin SP, Read HJ. The Biology of Millipedes. Oxford University Press, United Kingdom, 1992.

2. Cooper MI. Sexual size dimorphism and corroboration of Rensch's rule in Chersastus millipedes (Diplopoda: Pachybolidae). Journal of Entomology and Zoology Studies, 2014; 2:264-266.

3. Telford SR, Dangerfield JM. Sex in millipedes: Laboratory studies on sexual selection. Journal of Biological Education, 1990; 24:233-238.

4. Zar JH. Biostatistical Analysis. Prentice-Hall, New Jersey, 1984, 123.

5. Enghoff H. The Size of a Millipede. 8th International Congress of Myriapodology, Innsbruck, Austria, July 15-20. Acta Myriapodology, 1992, 47-56.

6. Rowe M. Copulation, mating system and sexual dimorphism in an Australian millipede, Cladethosoma clarum. Australian Journal of Zoology. 2010; 58(2):127132. 